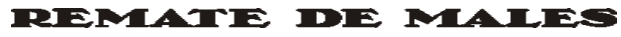

Campinas-SP, v.38, n.2, pp. 990-1017, jul./dez. 2018

\title{
A estreia literária de SÉrgio Milliet: PAR LE SENTIER
}

\author{
Valter Cesar Pinheiro
}

\begin{abstract}
Resumo: Em 1917, em Genebra, Sérgio Milliet lançou uma coletânea de versos neorromântico-simbolistas escritos "à maneira de" Baudelaire, Verlaine e Samain: Par le sentier. Ausente do acervo das principais bibliotecas do país, a obra inaugural de um dos maiores nomes da crítica literária e artística brasileira do século XX permanece desconhecida do público leitor. Assim, converte-se no principal objetivo do presente texto apresentar alguns comentários acerca desse livro de estreia, aos quais se acrescentam apontamentos de caráter biográfico relativos à primeira passagem do autor pela Europa e notas alusivas ao Carmel, grupo literário responsável pela revista em que Milliet publicou seus primeiros poemas e pela editora que colocou Par le sentier em circulação.

Palavras-chave: Sérgio Milliet; poesia; Simbolismo.
\end{abstract}

Em 1917, em Genebra, Sérgio Milliet da Costa e Silva (1898-1966) debutava na literatura com um volume de versos escritos em língua francesa: Par le sentier. Milliet irrompia no mercado editorial com o nome grafado à francesa - Serge -, e tal fato se repetiria, nos anos imediatamente subsequentes à publicação da obra de estreia, tanto nos livros (En singeant...: pastiches littéraires, Le départ sous la pluie, Gil de bœuf) quanto em colaborações avulsas em revistas europeias. O título foi lançado pela editora do círculo literário que animava Le Carmel, periódico com o qual, na companhia de autores como Romain Rolland e Carl Spitteler (vencedores do Prêmio Nobel de Literatura em 1915 e 1919, respectivamente), contribuiu o jovem poeta paulistano.

1 Professor do Departamento de Letras Estrangeiras da Universidade Federal de Sergipe (UFS): <valterpinheiro@yahoo.com.br>. 
Poeta? Tão trezentos ou trezentos e cinquenta quanto o amigo e parceiro modernista Mário de Andrade, foi como crítico de arte, entretanto, que firmou seu nome no mundo das letras o também ensaísta, ficcionista, jornalista, pintor, tradutor, professor, sociólogo, crítico literário, bibliotecário e homem de gabinete Sérgio Milliet. Se, de sua vastíssima bibliografia, o Roteiro do café: análise histórico-demográfica da expansão cafeeira no estado de São Paulo é o livro que mais ganhou reedições (lançado em 1938, foi reimpresso em 1939, 1941, 1946 e 1982), são, contudo, os dez volumes do Diário crítico, única obra do autor, ao lado do título sobredito e de Marginalidade da Pintura Moderna, a ter voltado ao prelo (publicados entre 1944 e 1959, os volumes foram reeditados em 1981), e os textos direcionados para as artes plásticas dentre os quais sobressaem Pintores e pinturas (1940), o mencionado Marginalidade da Pintura Moderna (1942), A pintura norte-americana: bosquejo da evolução da pintura nos Estados Unidos (1943) e Pintura quase sempre (1944) - que têm atraído maior atenção dos leitores e pesquisadores. Com efeito, observa-se, pela relevância dos estudos no campo das artes plásticas (sobretudo em sua vertente historiográfica) em que há alusão aos supracitados escritos de Milliet, que estes, pelo pioneirismo, acuidade e sensibilidade, se mantêm como referência obrigatória para aqueles que produzem, investigam e interpretam as artes plásticas no Brasil, e têm, por conseguinte, uma fortuna crítica bastante significativa.

Conquanto não se pretenda estender-se longamente nessa matéria, faz-se mister destacar - menos como evidência do que ora se afirma do que registro de uma importante fonte bibliográfica - um desses estudos: Sérgio Milliet - 100 anos: trajetória, crítica de arte e ação cultural, volume que abre a Coleção Crítica de Arte lançada em 2004 pela Associação Brasileira de Críticos de Arte. Nesse tributo ao principal mentor e primeiro presidente da $\mathrm{ABCA}$, resgata-se a comunicação pioneira de Antonio Candido, "Sérgio Milliet, crítico", de 1978, e o supradito ensaio Marginalidade da Pintura Moderna, da lavra do autor homenageado. Dos estudos dedicados à obra do polígrafo paulistano que ganharam edição em livro, aponta-se, por fim, Sérgio Milliet, crítico de arte (GONÇALVES, 1992) e Ceticismo e responsabilidade: Gide e Montaigne na obra crítica de Sérgio Milliet (CAMPOS, 1996), que abordam essencialmente a ensaística do autor do Diário crítico e sua correspondência (apenas parcialmente editada). 
A produção crítica de Sérgio Milliet cuja publicação é anterior ao Diário crítico não é, todavia, posta à margem pelos acadêmicos: Términus seco e Outros cocktails (1932), Marcha a ré (1936) e Ensaios (1938) são ocasionalmente mencionados (mormente como subsídio para o entendimento das obras editadas a partir dos anos 1940), assim como o são a análise e a tradução em língua francesa de poemas brasileiros lançadas em revistas europeias nos "frementes anos 20", citadas, sobretudo, em estudos que avançam na seara das relações literárias franco-brasileiras. ${ }^{2}$ No entanto, sua escrita ficcional e poética, que abrange um apreciável número de títulos publicados ao longo da vida, do precursor Par le sentier, de 1917, às Cartas à dançarina, de 1959, passando por Roberto, narrativa de 1935, permanece pouquíssimo estudada.

Para Alambert Júnior (1991), o vínculo de Sérgio Milliet com os demais partícipes do grupo modernista - questão sobre a qual boa parcela da crítica emudece - seria marcado, ao menos na fase iconoclasta do movimento, pela não adesão do poeta (atestada pelos reiterados e insistentes pedidos de Mário de Andrade para que Milliet retornasse ao Brasil e escrevesse em português) ao programa nacionalista de seus colegas, o que talvez justifique o escasso número de pesquisas que tenham por alvo seu espólio literário. Vale ressaltar que Milliet teria, como obliquamente afirma o autor de Macunaíma na famosa conferência de 1942, sido um grande crítico do movimento que se consagraria em nossa historiografia literária, ${ }^{3}$ o que também explica, no mínimo parcialmente, o "exílio" (para recuperar o termo empregado por Alambert Júnior) ao qual foram condenados o autor e sua obra.

A produção poética de Sérgio Milliet escrita em língua francesa mantém-se, portanto, em sua quase totalidade inexplora-

\footnotetext{
2 Tomem-se os artigos (em forma epistolar) de Milliet que tinham por objetivo divulgar a moderna literatura brasileira na Bélgica, "Une semaine d’art moderne à São Paulo" e "La jeune littérature brésilienne”: lançados na revista Lumière em 1922, foram traduzidos por Marta Rossetti Batista, publicados na Revista do Instituto de Estudos Brasileiros (n. 34, 1994, pp. 199-210) e mais tarde relançados em 22 por 22: a Semana de Arte Moderna vista pelos seus contemporâneos (BOAVENTURA, 2010). As relações entre os modernistas paulistanos e seus congêneres belgas foram examinadas em "Klaxon e Lumière" (LARA, 1975) e "Revistas e redes literárias: reflexões sobre a Lumière" (VELLOSO, 2016).

3 A turma de modernistas de primeira hora vivia em permanente "estado de exaltação". "Apenas Sérgio Milliet”, que havia voltado "sabidíssimo da Europa”, "punha um certo mal-estar no incêndio, com a sua serenidade equilibrada” (ANDRADE, 1978, pp. 237-238).
} 
da, ${ }^{4}$ a despeito da ênfase dada pelos críticos à magnitude das relações do escritor paulistano com o mundo francófono, laços que, como afiança Gonçalves (1992), estariam no bojo do "cosmopolitismo" e da "vocação europeia" do autor. É importante acentuar que parte das obras de sua "fase francesa" - notadamente os livros publicados no final da década de 1910 - sequer integra o acervo das principais bibliotecas brasileiras. ${ }^{5}$ Se esse fato, por um lado, determina a razão pela qual não há estudos consagrados à obra imatura de Milliet, revela, por outro, o quão desconhecidos são esses títulos do leitor (especializado ou não), porquanto ausentes de nossas prateleiras.

Assim, converte-se no principal objetivo do presente texto apresentar alguns comentários acerca da obra inaugural de Sérgio Milliet, Par le sentier, antecedidos por breves apontamentos de cunho biográfico relativos à primeira passagem do autor pela Europa e notas alusivas à revista Le Carmel e ao cenáculo que a mantinha em circulação.

Órfão de mãe ${ }^{6}$ aos dois anos de idade, Sérgio Milliet foi criado pela avó materna. Aos catorze, foi enviado à Suíça estudar Ciências Econômicas e Sociais na Escola de Comércio de Genebra (tendo, todavia, concluído seus estudos na cidade de Berna). Permaneceu

4 Alguns desses escritos ("Boîte à souvenirs", Eil de bœuf e três poemas publicados na revista Klaxon), antecedidos de um valiosíssimo estudo introdutório, foram reeditados por Antoine Chareyre: Poèmes modernistes \& autres écrits (MILLIET, 2010). Ramos (1968), em discurso de posse na Academia Paulista de Letras, também alude, de modo sucinto, aos primeiros livros de Sérgio Milliet.

5 Foram consultados os fundos das bibliotecas das universidades paulistas (USP, banco de dados bibliográficos Dedalus; Unicamp, base Acervus; Unesp, banco de dados Athena), das Academias Paulista e Brasileira de Letras, da Fundação Biblioteca Nacional e da Biblioteca Municipal Mário de Andrade. Foi explorado, igualmente, o sítio de venda de livros usados Estante Virtual (<www.estantevirtual.com.br $>$ ). O volume de Par le sentier a que se teve acesso integra o acervo bibliotecário da Universidade de Genebra.

6 A mãe de Sérgio, Aída Milliet, era filha de Alphonse Auguste Robert Gumble Milliet, agente consular da França em São Paulo (e, à guisa de curiosidade, proprietário da "Casa de Dona Yayá” - que atualmente sedia o Centro de Preservação Cultural da USP - e de uma parte da "Chácara do Capão", correspondente a uma área que vai da região central paulistana à Avenida Paulista, no eixo da atual Rua Augusta). Sobre as origens de Sérgio Milliet, v. A crítica bandeirante: 1920-1950 (SERRANO, 2016), Vivre à St. Paul: os imigrantes franceses na São Paulo oitocentista (BIVAR, 2007) e o supramencionado discurso de Péricles Eugênio da Silva Ramos. 
no Velho Continente por quase dez anos. Voltou ao Brasil em 1922,7 mas, já no ano seguinte, deu início a uma segunda longa temporada na Europa (estabelecendo-se, desta feita, em Paris), de que só retornaria em 1925. Conquanto não haja consenso quanto ao grau de inserção de Milliet junto às hostes modernistas paulistanas nos primeiros anos da década de 1920 (questão cujo exame tem de ser feito com cautela, como atestam Alambert Júnior em seu supramencionado estudo e Renata Rufino da Silva em diversos artigos sobre o autor), pode lhe ser de forma inconteste outorgado - por ter divulgado em revistas literárias traduções em língua francesa de poemas de Oswald de Andrade, Guilherme de Almeida, Mário de Andrade e Manuel Bandeira, entre outros - o título de maior difusor da nova literatura brasileira em terras europeias. É o futuro autor de Pau-Brasil, Oswald de Andrade (1922, apud BRITO, 1972, [s.p.]) que lhe reconheceria, aliás, o papel de principal intermediário entre o grupo de São Paulo e os congêneres europeus:

Sérgio Milliet mantém o consulado mental paulista em centros europeus, trocando correspondência com Romain Rolland, Charles Vildrac, Baudouin, Avermaete e outros fortes espíritos contemporâneos e colaborando continuamente na Lumière, por onde vai vulgarizando os novos brasileiros. ${ }^{8}$

É pela narrativa autoficcional Roberto que se pode mais facilmente depreender o que supostamente foram, em São Paulo e em Genebra, a infância e a adolescência do filho de Fernando da Costa e Silva e Aída Milliet (metamorfoseado no protagonista que dá nome ao romance), a

\footnotetext{
7 Tendo regressado a tempo de participar da Semana de Arte Moderna (evento no qual foram recitados, pelo amigo Henri Mugnier, versos de (Eil de bœuf) e de associar-se à equipe de Klaxon, revista em que publicou, ainda sob a alcunha de Serge Milliet, seis poemas em francês e, com as iniciais S. M., resenhas de obras de Bob Claessens e Louis Emié, impressas pela editora do grupo de Lumière. Como já afirmado, Milliet também colaborou nesse periódico, fundado por Claessens e Avermaete em 1919 na cidade de Antuérpia.

8 Esse excerto de Oswald de Andrade está no texto "Senhor Dom Torres e Arte Moderna", Jornal do Commercio (Edição de São Paulo), 14/05/1922, citado por Brito (1972, [s.p.]) em "O alegre combate de Klaxon", texto introdutório da edição fac-similada da revista. Antonio Candido, em depoimento para a Plataforma da Nova Geração (série de testemunhos organizada por Mário Neme, publicada inicialmente no jornal O Estado de S. Paulo e lançada em livro em 1945), referira-se a Milliet, então com 45 anos, como o "homemponte" de duas gerações. Â acepção do termo empregado por Oswald, de caráter espacial, sobrepõe-se, portanto, o sentido cronológico da expressão cunhada por Candido. Sobre o papel de Milliet como mediador cultural, ver "O 'contra-modernismo': internacionalismo e mediação cultural de Sérgio Milliet nos anos 1920” (SILVA, 2015).
} 
despeito do que nos quis fazer crer o autor na nota introdutória: "Roberto não é autobiografia. Nem tampouco romance 'a chave'. [...] Uma tal explicação aqui fica expressa apenas por dever de lealdade, pouco se me dando que nela acreditem ou não" (MILLIET, 1935, p. 5). Roberto, como o escritor, perde a mãe aos dois anos e vive com a avó. O pai, assim que se vê viúvo, parte pelo interior do Estado, voltando tempos depois à capital "enroscado numa morena de olhos fundos" com quem se casa e tem filhos. O senso de paternidade lhe incute a ideia de trazer para o seio da família o primogênito que enjeitara. Roberto, por seu turno, repudia sua nova condição. Sem que se saiba o motivo, o pai, que lhe é indiferente, decide tirá-lo do ginásio ("Não dava para o estudo") e fazê-lo trabalhar. São as agitações e discussões que se seguem que exortam a família a enfrentar a decisão paterna e a enviar o garoto à Suíça, ${ }^{9}$ às expensas da herança da recém-falecida avó materna.

Roberto, às voltas com sua formação acadêmica e afetiva, escreve poemas e insere-se em um círculo interessado por literatura, artes e filosofia. Do grupo fazem parte Karl Reiber, Jean Roseler, Louis Badin, em cuja casa - modesta, de difícil acesso, mas com uma bela vista sobre o Jura - o grupo se reúne, um "outro" que se autodenomina "filósofo da estrofe e da antiestrofe, inventor do terceiro sexo e da quarta dimensão" e Henri Murget. Tais personagens por certo aludem a Charles Reber; a Jean Violette (bibliotecário da Universidade de Genebra); a Charles Baudouin, que, como confirma uma passagem do Diário crítico citada adiante, acolhia os integrantes de Le Carmel em seu endereço; a Camille Spiess, que, segundo a paródia que abre o volume de pastichos En singeant, apresentava-se como "filósofo da estrofe, da antiestrofe e da catástrofe, inventor do terceiro sexo, complexo, perplexo e circunflexo e da quarta dimensão sem noção de espaço" (MILLIET; REBER, 1918, p. 9);10 e a Henri Mugnier." Tal qual o alter ego protagonista do romance, Sérgio

9 Feito que ecoa em De ontem, de hoje e de sempre: recordações com devaneios: "Eu não dava para o estudo, pensava meu pai. Creio que foi para desmenti-lo que na Suíça, mais tarde, tirei todos os prêmios de literatura francesa. E o velho Graz, pai do nosso John Graz, e meu professor então, dizia que era uma vergonha: um estrangeiro primeiro da classe em francês! [...] Aquela consagração no estrangeiro compensava-me sem dúvida das humilhações da infância” (MILLIET, 1962, p. 111).

10 "[...] philosophe de la strophe, de l'antistrophe et de la catastrophe, inventeur du troisième sexe, complexe, perplexe et circonflexe, de la quatrième dimension sans notion de l'espace".

11 Campos (2004), em "Sérgio Milliet e Henri Mugnier, uma amizade duradoura”, aponta as semelhanças - de ordem física, psicológica e social - entre Mugnier e Murget. 
realiza sua educação sentimental e intelectual na cidade de Calvino, e é o companheiro Henri Mugnier quem muito presumivelmente o convida a integrar o rol de colaboradores de um novíssimo periódico literário local, Le Carmel. Passemos, então, essa revista em revista.

"Revue mensuelle de littérature, de philosophie et d'art", Le Carmel foi criada em fevereiro de 1916. O primeiro número foi lançado no mês de abril

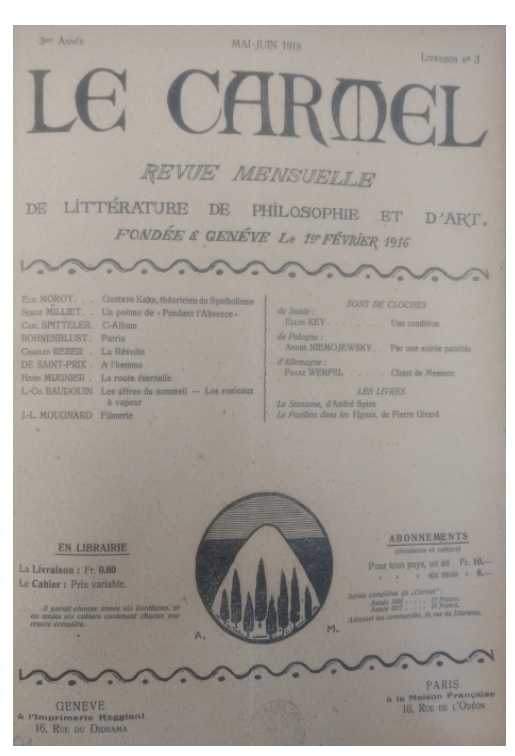

Figura 1 . Primeira página do último número da revista Le Carmel (maio-junho de 1918). No sumário, lê-se: Serge Milliet - "Un poème de 'Pendant l'Absence"” (que será uma das partes de Le départ sous la pluie, publicado em 1919).

Fonte: Foto de arquivo pessoal do autor. do mesmo ano, e o último (vigésimoprimeiro), dois anos depois, em junho de 1918. Deve-se a Blum (1997; 1998) os dois únicos estudos que têm Le Carmel por objeto de investigação e que se conseguiu localizar. É deles, por conseguinte, que provém, senão unicamente - posto que se fará menção aos modestos registros ao periódico encontrados em textos de Sérgio Milliet -, parte significativa do que segue nos parágrafos seguintes. ${ }^{12}$

Independente - condição para a qual contribuiu seu privilegiado local de publicação: a neutra Suíça e equidistante de igrejas literárias e agrupamentos políticos que vicejavam por toda a Europa no decurso da Primeira Grande Guerra, Le Carmel, idealizada por Charles Baudouin ${ }^{13}$ (que, após ter sido dispensado pelas Forças Armadas francesas em razão de sua frágil saúde, partira para o país vizinho para tratar dos pulmões e, segundo ele mesmo, conhecer Romain Rolland), ansiava ser a tribuna de todas as vozes livres.

12 Compulsaram-se, para a execução deste trabalho, os números de Le Carmel que conserva a biblioteca da Universidade de Genebra. A coleção está incompleta.

13 Escritor e psicanalista franco-suíço, Louis Charles Baudouin (Nancy, França - 1893; Saconnex-d'Arve, Suíça - 1963) foi professor da Universidade de Genebra. Sua extensa produção bibliográfica abrange os mais diversos domínios, com destaque para a Psicanálise, a tradução (transpôs obras de Carl Spitteler e Goethe para o francês), a ficção e a lírica. Pelas Éditions du Carmel, publicou Romain Rolland calomnié (1918) e quatro livros de poesia: Éclats d'obus (1917), L’Arche flottante (1919), Baptismales (1919) e Ecce homo (1921). 
Três nomes encabeçavam sua realização: sob a batuta do idealizador, figuravam igualmente o russo André Iossa e o jovem poeta franco-suíço Henri Mugnier. ${ }^{14} \mathrm{O}$ nome da revista viria de um poema de título análogo (estampado no livro de estreia, En sourdine, de 1915), no qual Baudouin aludia a um convento contíguo à sua residência em Nancy. Na página de abertura do primeiro número da revista, explicitava-se a intenção de seus criadores: fundar, com e pela publicação, um "asilo interior" que, por sua autonomia e distanciamento, permitisse a seus integrantes expressar com liberdade e precisão aquele conturbado momento histórico.

Ao grupo genebrino associaram-se Spitteler (autor do maior número de textos veiculados no periódico), Romain Rolland (não obstante sua recusa em apoiar oficialmente a iniciativa), Stefan Zweig, o pintor Alexandre Mairet (responsável pela crítica de arte e pelas reproduções impressas no periódico), ${ }^{15}$ Pierre Jean Jouve e Philéas Lebesgue, para citar os mais famosos, aos quais se somam Nietzsche e Tolstói, mortos em 1900 e 1910, que tiveram fragmentos de suas obras estampados nas páginas de Le Carmel em diversas ocasiões. Escritores e poetas locais - com especial destaque para o "grupo de Jean Violette":.16 Henry Spiess, René d'Helbingue, Pierre Girard, Charles Reber, Sérgio Milliet (cujo nome, assinale-se, não

14 Não se localizou nos dicionários literários compulsados nenhum dado relativo a Henri Mugnier (1890-1957). Dois de seus livros de poesia saíram pela editora do grupo Le Carmel: La clairière automnale (1917) e Paroles d'amour (1919).

15 Blum (1998, p. 74) reporta-se à crítica de Mairet nos seguintes termos: "Alexandre Mairet não separa estética de moral. Para ele, um grande artista deve expressar em sua obra o amor pela humanidade, pelo povo, por sua dignidade, sofrimento e labor, e um de seus modelos favoritos é o autor do célebre Angélus [Jean-François Millet]" [Alexandre Mairet ne peut séparer l'esthétique de la morale. Selon lui, un grand artiste doit exprimer dans son œuvre son amour de l'humanité, du peuple, de sa dignité, de sa souffrance, de son labeur, et l'un de ses modèles favoris est l'auteur du célèbre Angélus]. O cotejo entre os escritos de Mairet - bem como os de Aurel, pseudônimo de Aurélie de Faucamberge publicados em Le Carmel e os do autor do Diário crítico pode, parece-nos, trazer novas perspectivas àqueles que estudam a crítica de arte de Sérgio Milliet.

16 Jean Violette (Zurique - 1876; Genebra - 1964), autor de vasta e diversificada obra (peças de teatro, poesia, história), notabilizou-se como fundador, em 1894, do grupo que levou seu nome. A história desse coletivo de escritores foi retraçada em Un modeste cénacle littéraire, opúsculo editado em 1952. Milliet é por duas vezes citado nesse depoimento: como um dos presentes no banquete comemorativo dos vinte e cinco anos de fundação do cenáculo, em 27 de fevereiro de 1919, e como um dos versejadores do grupo: "Serge Milliet, que se tornou um figurão entre os escritores brasileiros, deixou-nos, antes de partir, um florilégio melancólico: Le départ sous la pluie" [Serge Milliet, devenu manitou parmi les écrivains brésiliens, avant son exil, il nous a laissé un florilège mélancolique: Le départ sous la pluie] (VIOLETTE, 1952, p. 11). No ano de lançamento de Par le sentier, Violette publicou, pelas Éditions du Carmel, Sous l'armure. 
aparece nos artigos de Antoinette Blum) e outros - teriam sido levados à revista por Henri Mugnier.

Para Blum (1998), são os textos que apresentam conteúdo político aqueles que justificam a importância do periódico para o leitor de hoje, visto que no plano literário ou artístico Le Carmel não ocupou posição de relevo nos meios vanguardistas (como evidenciam, aliás, os poemas assinados por Milliet). Ataques à revista (sobretudo ao grupo de Mugnier e Violette, o "clã franco-chauvinista" dos carmelitas) e dificuldades financeiras levaram ao fim de sua difusão em junho de 1918. No mês seguinte, Baudouin passa a chefia da edição a Charles Reber - com quem Milliet publica, no mesmo ano, En singeant...: pastiches littéraires, coletânea de textos que parodiam a escrita de integrantes do grupo violettiano -, sem que, no entanto, novos números de Le Carmel sejam publicados.

O periódico é mencionado por Milliet ao menos três vezes em seus escritos: em "Romain Rolland", décimo-terceiro capítulo dos Ensaios (1938), no oitavo volume do Diário crítico (1953) e no estudo dedicado à obra de Émile Verhaeren, "Um poeta da vida moderna", que integra Quatro ensaios (1966).

No primeiro, Milliet percorre - com alguma riqueza de pormenores - o período em que conheceu Romain Rolland, publicou seu livro inicial e colaborou na revista de Baudouin. A citação é longa, mas merece ser reproduzida:

Exatamente com dezoitos anos, ainda estudante da Universidade de Genebra, publicava meu primeiro livro de poesias: Par le sentier. Eu era um sofredor, por temperamento e circunstâncias momentâneas, um sofredor apaixonado, cujos versos se ressentiam ainda da época miserável que atravessava a Europa. Genebra era então um covil de espionagem. Digladiavam-se as "Intelligence Services” das diferentes nações em guerra, numa atmosfera de ódios e intrigas. Mas era, também, um dos raros recantos neutros em que se podiam refugiar os incompreendidos, os que a imbecilidade desencadeada dos homens repudiava. Exilados, viviam ali os grandes feridos de guerra, os que, inúteis para a carnificina, os adversários trocavam "humanamente" como peças de moeda olho por olho - fuzil por fuzil...

Em 1917 já se sentiam os homens cansados da glória e desiludidos das demagogias oficiais. Muitos escândalos, filtrados através das confidências dos informados, haviam reduzido os "ideais" delirantes às suas devidas proporções. Foi quando se fundou a revista Le Carmel, sob a direção de Louis Charles Baudouin, ferido de guerra em tratamento na Suíça. Tinha por fim servir de porta-voz aos intelectuais de ambas as facções, para que, isentos de paixão, pudessem com franqueza e lealdade expor seu verdadeiro pensamento. Em suas colunas defenderam causas diversas alguns dos mais belos espíritos da época. E por seu intermédio puderam corresponder homens situados em campos opostos, 
como Verhaeren e Stefan Zweig. Além destes, colaboraram seguidamente na revista o grande poeta suíço Carl Spitteler, os franceses Édouard Dujardin e Pierre Jean Jouve, o flamengo Frans Masereel, o alsaciano Yvan Goll, os genebrinos Jean Violette, Henry Spiess e Henri Mugnier. Charles Reber e eu formávamos a ala mais moça do grupo, cujo chefe, Louis Charles Baudouin, hoje livre-docente da Universidade de Genebra, não tinha ainda trinta anos. Dava-nos Romain Rolland o apoio de seu nome mundialmente conhecido, ao mesmo tempo que o adjutório material da cessão dos direitos de autor sobre as obras dele que editávamos. [...] Residia num arrabalde da cidade e somente por correspondência o atingíamos. (MILLIET, 1938, pp. 188-189)

Voltar-se-á mais tarde aos comentários do autor sobre Par le sentier. Por ora, sublinham-se, no trecho supracitado, as notas a respeito de Le Carmel: origem, objetivo e participantes. Todavia, decorridos vinte anos do fechamento da revista, Milliet acaba por equivocar-se tanto acerca de sua data de fundação, erro talvez assentado no fato de que só no primeiro número de 1917 um escrito seu despontaria nas páginas do periódico, quanto ao que parece ter sido o real aporte de Romain Rolland à publicação (lapso justificável se se considerar que esse texto, como indica o título, rende homenagem ao autor de Jean-Christophe).

Em 14 de fevereiro de 1952, Milliet, motivado pela leitura de Romain Rolland, de René Arcos (1950), afirma:

Neste livro de Arcos há uma referência à revista Le Carmel que se editava então em Genebra sob a direção de Charles Baudouin e em cuja redação trabalhei. Éramos pacifistas e a nosso lado se achavam Stefan Zweig, Carl Spitteler, René Arcos, Guilbeaux, boa parte dos escritores que mais tarde fundaram Europe. Reunia-se o grupo aos domingos na colina de Saconnex d'Arve perto de Genebra, à qual se tinha acesso por uma estrada sinuosa entre vinhedos e plantações de macieiras. Do alto da casa modestíssima de Charles Baudouin, um simples atelier gelado, avistava-se a cidade, o lago, o Jura no último plano. (MILLIET, 1981c, pp. 165-166)

Nenhuma menção, nessa passagem do Diário, à rivalidade entre os grupos de Mugnier - ao qual pertencia Sérgio Milliet - e Guilbeaux, disputa que teria, de acordo com Blum (1998, pp. 80-81), igualmente contribuído para o encerramento da revista. De resto, a designação da residência de Charles Baudouin como quartel-general dos integrantes do cenáculo não se configura exatamente como um dado novo, pois tal informação, como já destacado, aparece, ainda que de modo ficcional, em Roberto.

Por fim, cita-se uma pequena passagem de "Um poeta da vida moderna” (Quatro ensaios), livro publicado postumamente, mas que fora inteiramente revisto pelo autor. Entende-se, pelo que já foi exposto, 
que a primeira pessoa do plural de que se serve Milliet (1966, p. 81, grifos nossos) tange ao coletivo genebrino como um todo, e não ao grupo de Violette em particular:

Conheci Verhaeren de passagem por Genebra. Eu era uma criança e mal começava a me entusiasmar pelos poetas. Vi-o de relance, a cabeça gaulesa sob um largo chapéu de feltro. Nunca lhe falei, mas a seu respeito me entretive com Stefan Zweig, Charles Baudouin e Henri Mugnier, seus amigos e discípulos refugiados na Suíça neutra de 1915-16. Havíamos fundado a revista Le Carmel que seguia a orientação de Romain Rolland e procurava unir num programa de fraternidade os espíritos superiores da Europa.

Foram identificados em Le Carmel quatro textos que levam a assinatura de Sérgio Milliet:

- "La Chimère", soneto dedicado a Henri Mugnier (n. 1, jan. 1917). O poema, atribuído a "Serge Costa", apresenta uma data de composição incompatível com a do lançamento da revista: 31 de março de 1917. De duas, uma: ou houve atraso na impressão do periódico, ou se trata de um equívoco de outra ordem (erro de composição ou de datação);

- "Au clair soleil de cette automne..." (n. 9, nov./dez. 1917), poema ofertado a Jean Violette;

- "Poème", dedicado a Henry Spiess. Como os fascículos de Le Carmel aos quais se teve acesso foram encadernados em um só tomo (e algumas de suas capas, suprimidas), não foi possível precisar o número da revista no qual saíram esses versos. A data de composição (29.10.1917) e o lugar que ocupa no volume (após "Au clair soleil de cette automne...") indicam sua edição apenas em 1918;

- "Un poème de 'Pendant l'Absence”' (n. 3, mai./jun. 1918). Esse poema, sem título, integra Le départ sous la pluie, lançado em 1919.

A admissão ao grupo Le Carmel (que englobava a congregação de poetas, a revista e a editora) permite ao jovem paulistano não apenas encontrar leitores para seus escritos, mas igualmente alcançar o meio de divulgá-los. O gosto e o pendor artístico de Milliet decerto sofreram o impacto de discussões acaloradas entabuladas pelos carmelitas nos arredores das gélidas montanhas do Jura, e, não por acaso, alguns dos membros do cenáculo têm seus nomes estampados em Par le sentier. 
Sérgio Milliet será, reitere-se, o maior propagador de obras e de autores brasileiros na Europa nos anos subsequentes à publicação de seu primeiro livro. No entanto, quem o acolhe e lhe dá voz, nesse momento, é o círculo de escritores, leitores e críticos de Genebra. Le Carmel e Par le sentier tornam-se, assim, indissociáveis.

Segue, para concluir este prelúdio, a transcrição do primeiro poema de Milliet que veio a lume em Le Carmel. Esses versos reaparecerão, sem título ou dedicatória, nas páginas do livro de estreia.

\section{La Chimère}

Sous la lampe voilée, au milieu des coussins, Pâle, les yeux mi-clos, la pose languissante, La Chimère s'endort - merveilleuse Bacchante Et les illusions s'abreuvent à ses seins.

Les poètes - enfants soumis à des desseins Grandioses et fous - l'haleine haletante, Cherchent à conserver cette toison puissante Qui tombe en boucles d'or, en ourlets sarrasins,

De sa tête féline et pleine de tendresse.

Elle laisse approcher et douce elle caresse

D'un regard enivrant les beaux aventuriers;

Mais tout à coup, farouche, elle montre ses ongles, Et comme une tigresse habitant dans les jungles Les arrache à la gloire et brise leurs lauriers. ${ }^{17}$

No ano em que Apollinaire pronuncia L'esprit nouveau et les poètes, Valéry publica La jeune parque e é encenado em Paris o balé Parade, criação coletiva de Satie, Cocteau, Picasso, Diaghilev e outros, Milliet publica nas páginas de Le Carmel esse soneto de feições simbolistas.

17 "A Quimera”: "Sob uma turva luz, deitada em finos panos,/ Pálida, olhos entreabertos, em pose inebriante,/ A Quimera adormece - estupenda Bacante -/ E nutrem-se em seus seios à farta os enganos.//

Os poetas - crianças tomadas por insanos/ E gigantes desejos - em suspiro ofegante,/ Intentam conservar esta crina pujante/ Que pende em cachos áureos, em galões muçulmanos,// Da cabeça felina e cheia de ternura./ Ela deixa achegarem, e mima com doçura/ E um sedutor olhar os belos destemidos;// Mas de súbito, indomável, ela as garras acera,/ E tal fera da selva, assombrosa pantera,/ Arranca-lhes a glória e os louros recebidos". (MILLIET, 1917, p. 25). A partir de agora, todas as citações dessa obra serão dadas apenas com a página. Todas as traduções deste artigo são nossas, salvo quando indicado em contrário. 
Nele, o jovem que, anos mais tarde, converter-se-á em um dos arautos da arte moderna no Brasil recupera - em ótima realização ${ }^{18}$ para um principiante - o prolífero mito da Quimera. Os poetas, comparados por sua imaginação e idealismo a crianças, não sobrevivem ao ardil da criatura fantástica. Tema presente em um número infindável de poemas de todas as épocas, a quimera serviu igualmente de inspiração a um autor cuja voz ressoa no sentier millietiano: Albert Samain. ${ }^{19}$

Par le sentier apresenta-se aos leitores envolto em uma capa cuja sobriedade, assegurada pelo escolha de um papel de matiz pardo

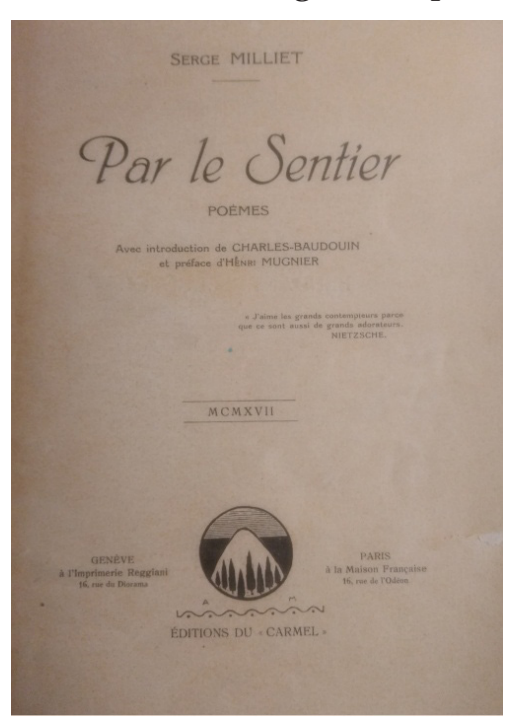

Figura 2 . Capa de Par le sentier.

Fonte: foto de arquivo pessoal do autor (tirada de exemplar da Biblioteca Nacional de Genebra). claro, é inversamente proporcional à prodigalidade de dados paratextuais ali impressos: às indicações de autor, título, subtítulo remático de feição clássica "Poèmes" -, ano de publicação e editora (cuja logomarca, ladeada pelos endereços de correspondência em Genebra e em Paris, reproduz um monte nevado flanqueado de pinheiros à beira do lago Léman), acrescentam-se, em lugar de relevo - no centro da página, conquanto estampados em caracteres de dimensões mínimas -, prefaciadores e uma inusitada epígrafe, de autoria do "filósofo de predileção" da revista Le Carmel (BLUM, 1998, p. 75), Nietzsche. ${ }^{20}$

18 Infelizmente conspurcada por um descuido na concepção das rimas masculinas dos quartetos.

19 Cf. "La Chimère" (Le chariot d'or - symphonie héroïque, 1901).

20 O filósofo alemão teve variados fragmentos de sua obra - e um estudo crítico realizado por Charles Baudouin - impressos nas páginas do periódico suíço. A epígrafe de Par le sentier, "J'aime les grands contempteurs parce que ce sont aussi de grands adorateurs" [Amo os grandes depreciadores, porque são os grandes adoradores] foi extraída de Assim falava Zaratustra, cuja primeira publicação em língua francesa data de 1892. Sobre a recepção da obra nietzschiana na França no último decênio do século XIX - e mais particularmente entre os simbolistas -, ver Décaudin (1981, pp. 46-48). Em tempo: Milliet assinará a tradução, em 1940, de O pensamento vivo de Nietzsche, de Heinrich Mann. 
No dorso da capa de Par le sentier anuncia-se o livro Pendant l'absence - e seu inequívoco subtítulo baudelairiano (Poèmes en prose) -, que não será editado. ${ }^{21} \mathrm{~A}$ falsa folha de rosto ostenta tão somente o título da obra, a que se somam, no volume consultado, uma dedicatória de exemplar - "À Charles Baudouin, souvenir affectueux. Serge Milliet, le 8-XI-17" -, o exlibris do autor francês e, colado no verso, um soneto manuscrito: "Charles Baudouin".

Quatro escritos interpolam-se entre a folha de rosto e a primeira das cinco partes de que a coletânea se compõe: os dois iniciais, em prosa, urdidos por mãosalheias, eos seguintes, em verso, da lavra do próprioautor. No primeiro, "Introduction", o redator Charles Baudouin frisa, ao revelar a origem de Milliet, que o francês não é a língua de berço do autor de Par le Sentier. O leitor, todavia, haveria de reconhecer que o jovem brasileiro dela se apropriou com mestria, incorporando-lhe a força, a essência, o espírito ("génie"). A sensibilidade amarga, ardente, doentia e macabra de Milliet faz com que o poeta se afigure aos olhos de Baudouin como um amálgama de Verlaine e Baudelaire, ${ }^{22}$ ou ainda, graças à perspectiva de força e alegria futura, prenunciada nos versos finais da coletânea, como um invulnerável Aquiles deixando as águas pútridas do Estige (à moda simbolista). A lamentar, nessa curta introdução, a previsível indicação do que seria a contribuição pessoal do poeta estrangeiro: evocando desta feita outro escritor francês, Leconte de Lisle, Baudouin atribui à poética do estreante cores quentes, meridionais e exóticas, ideia que, entretanto, não encontra guarida nos versos de Par le sentier. ${ }^{23}$

Henri Mugnier principia o segundo texto de apresentação do livro, "Préface", com um retrato construído a partir do relato do primeiro encontro com Milliet, em um café, no ano de publicação de Par le sentier: o brasileiro era um rapazalto, magro, moreno e de um olharvivo e inteligente,

21 No entanto, "Pendant l'absence" será, como afirmado na nota à figura 1, o título de uma das partes de Le départ sous la pluie (em que constam unicamente poemas de forma fixa), publicado em 1919.

22 Assinale-se que "amer", “ardent", "maladif” e "macabre”, bem como seus correlatos, numerosos nas Flores do mal, também estão presentes em Par le sentier, de que se cita, como exemplo, este verso do "Prélude": "Parce qu'elle me fit une âme ardente et triste" [Posto que ela [a natureza] me fez uma alma ardente e triste] (p. 16).

23 A única - e hipotética - alusão, sem que seja explicitado o nome do país de origem, à condição de estrangeiro de Milliet (p. 67), aparece no início do poema "J’ai laissé mon pays d'azur et de soleil": "J’ai laissé mon pays d'azur et de soleil/ Où l'Idéal revêt les formes les plus pures" [Eu deixei meu país de sol e céu anil/ Onde o Ideal cobre as mais puras das formas]. 
porém tímido. Seus modos, decerto acentuados pelo uso do tabaco inglês, davam-lhe um ar de "parfait gentleman". Mugnier afirma que já conhecia o jovem poeta, pois alguns de seus versos teriam sido difundidos em uma revista de estudantes brasileiros. ${ }^{24}$ Tornam-se amigos. Frequentam-se. Partilham sonhos, ilusões e o amor pela arte. Seguro de que os escritos de Milliet merecem o prelo, Mugnier submete-os a Baudouin.

Sincera, ardente, amarga e macabra: o autor do prefácio, ao caracterizar a expressão poética de Milliet, resgata os termos com os quais Baudouin definira a sensibilidade do escritor brasileiro. Para Mugnier, os versos do debutante revelariam com nitidez seu apreço por Baudelaire, Verlaine e Samain (os dois primeiros, igualmente mencionados por Baudouin), ou seja, teriam sido compostos, em alguma medida, "à maneira de”. O crítico rende-se ao ímpeto classificatório e filia o amigo - por sua sensibilidade, sensualidade e paixão, pela vida devotada às inclinações amorosas e à satisfação de impulsos físicos e mentais e por uma escrita etérea, perfumada, colorida e quente como o país de que é proveniente - aos decadentistas, sem, todavia, fazer nenhum tipo de alusão a traços tipicamente associados àquela corrente, como a crítica ao progresso e aos costumes burgueses ou a fuga à realidade.

Mugnier contrapõe àqueles que por ventura censurem a ocorrência, em Par le sentier, de locuções incomuns e palavras "ousadas" as virtudes de um escritor que ama a natureza e os homens (e, ao fazê-lo, termina por imprevistamente associar Milliet à escola naturista), que crê em si, na arte e - em um mundo devastado pela guerra - na poesia. Antevê, também, que haverá quem reprove o não engajamento do poeta: ao ignorar a carnificina que se espraia nos países circunvizinhos (o silêncio é, em si, uma tomada de posição), seus versos seriam outra coisa senão leviandade ou passatempo? Chega-se, nesse ponto, à questão mais importante do prefácio: defender a paz, em arte, implica necessariamente falar de guerra? Qual o lugar da poesia em um mundo cindido por lutas armadas? Milliet não tem, sublinha Mugnier, obrigações militares a cumprir em solo europeu e torna-se, ao fazer arte em tempos tão sombrios, um genuíno

24 "Houve um momento", afirmará o autor de Par le sentier, "em que a colônia brasileira era tão numerosa em Genebra que mantinha uma revista literária: La Revue du Brésil. Nela colaboravam Túlio Chaves (hoje no Rio), Atahualpa Lopes, Uflacker, Filogônio Lisboa, Débora Marcondes e alguns suíços amigos da turma” (MILLIET, 1962, p. 100). Não foram encontrados números desse periódico. 
apóstolo da paz, e seus poemas, nos quais rolam apenas lágrimas por ardores não correspondidos, uma verdadeira "obra de amor". 25

Esses escritos preliminares, compostos por parceiros da tertúlia genebrina, revelam, a despeito de suas modestas dimensões, como foi a acolhida pré-publicação da poesia de Sérgio Milliet pelo grupo da revista Le Carmel. Ambos os prólogos destacam mais a singularidade da origem do escritor - vinculando-a a um temperamento supostamente ardente do que propriamente sua escrita, na qual, em versos que têm por matéria as doridas experiências amorosas de um adolescente, transpareceriam - e não há aí nenhum traço peculiar ou exótico - as leituras de Baudelaire e Verlaine.

Aos textos de Baudouin e Mugnier pospõem-se dois poemas, "Dédicace" e "Prélude", cujo intuito, como os títulos evidenciam, é abrir a coletânea. No primeiro, o sujeito lírico invoca simultaneamente os leitores, a natureza, fiel espectadora de seus arroubos amorosos, e os versos que devem cantar tais arrebatamentos a testificarem seu amor, em sua dimensão lúgubre e trágica, pela mulher amada: "À toi mon cœur, à toi mes vers, à toi mon sort;/ L'amour que je te voue est plus grand que la Mort". ${ }^{26}$ No segundo, o eu lírico toma novamente por testemunhas de seu sofrimento amoroso os leitores, aos quais pede compaixão e compreensão e, mediante o uso de antíteses, ${ }^{27}$ lamenta sua vulnerabilidade às paixões. A natureza, entretanto, deu a essa voz - tal qual à congênere baudelairiana (seja a do tirano e vítima que padece de amor, seja a do inapto, abjeto, hilário e horrendo, posto que incompreendido, poeta-albatroz $)^{28}$ - "uma alma ardente e triste": uma alma de poeta.

25 Examinar mais profundamente os laços afetivos e intelectuais que unem Sérgio Milliet a Henri Mugnier não é o propósito deste trabalho (sobre essa relação de amizade, v. os supracitados artigos de Campos, 2004, e Velloso, 2016). Não obstante, vale ressaltar que em Par le sentier Mugnier se destaca, figurando não apenas como prefaciador do volume, mas também como dedicatário de "Lassitudes" e autor da epígrafe do poema "Amie, voici la saison belle".

26 "A ti meu coração, meus versos, minha sorte;/ O amor que lhe devoto é maior do que a Morte" (p. 13).

27 Dentre as quais se destacam: "Je suis au crépuscule et pourtant c'est l'aurore" [Eu estou no crepúsculo e no entanto é aurora] (p. 15), "des désirs endormis qui s'éveillent” [desejos adormecidos que despertam] (p. 15), "vivre calme au milieu de l'orage effrayant" [viver calmo no meio da terrível tormenta] (p. 16), "et répondre à seus pleurs par un rire stupide" [e replicar seus prantos com estúpido riso] (p. 16).

28 "Victime" e "bourreau" ("L'Héautontimorouménos"); "maladroit", "honteux", "comique" e "laid" ("L’albatros"). 
Car je suis celui-là qu'on se montre en riant, Celui qui rêve, pense et frémit et frissonne, Qui aime le printemps et adore l'automne, Car je suis le Poète : orgueilleux et souffrant. ${ }^{29}$ (MILLIET, 1917, p. 17)

Sucedem a "Dédicace" e "Prélude" quarenta e seis poemas. O conjunto divide-se em cinco seções de proporções distintas, "Idéal" [Ideal], "Demiteintes" [Meios-tons], "Le chemin des sens" [O caminho dos sentidos], "Lassitudes" [Lassidões] e "Vers la Joie" [Rumo à Alegria], dedicadas a Gaston Bahel, René Durel, Charles Baudouin, Henri Mugnier e T. Paço, respectivamente. No rol de homenageados, ${ }^{30}$ fulguram, portanto, os principais nomes da assembleia carmelita - Baudouin, Mugnier e Jean Violette (a quem "Prélude" é ofertado) -, autores que, como assinalado, igualmente publicaram versos pela editora do grupo em 1917. Ao longo da obra, Milliet também rende tributo, sob a forma de dedicatória de poema, a outras oito pessoas, dentre as quais Túlio Chaves, ${ }^{31}$ Georges Théodorovitch, ${ }^{32}$ o tio Horácio Sabino ${ }^{33}$ e, in memoriam, a mãe, Aída Milliet. ${ }^{34} \mathrm{O}$ jovem poeta, portanto, brinda seu livro de estreia com parceiros de Genebra, amigos brasileiros, mãe, tio materno e, supostamente, com

29 "Pois que sou eu aquele de quem ri toda a gente,/ Aquele que sonha e pensa e treme e estremece,/ Que preza a primavera e que o outono enaltece,/ Pois que sou eu Poeta: orgulhoso e sofrente." (p. 17).

30 Par le sentier não tem dedicatário de obra. Sobre Bahel - rapidamente mencionado no segundo volume de De ontem, de hoje e de sempre: "De passagem por Paris, no aeroporto de Orly, despedi-me há tempos de um amigo que não via há quarenta anos. [...] Pois esse amigo, Gaston Bahel, trouxe cartas que eu lhe enviara na juventude e que ele guardava com o carinho dos europeus pelas coisas de antanho" (MILLIET, 1962, p. 8) -, Durel e Paço não se encontraram dados biobibliográficos.

31 Túlio Chaves estudou Medicina em Genebra. Quatro sonetos seus saíram na revista Le Carmel (n. 1, jan./fev. 1918). É de sua autoria a epígrafe do soneto que Milliet lhe oferta.

32 Trata-se muito possivelmente de Georges Théodorovitch Sapunov (1899-1982), cuja família deixou a Rússia, sob a Revolução de 1917, com destino à França.

33 Horácio Sabino (1869-1950) foi casado com América Milliet, irmã de Aída. Loteou parte das terras herdadas do sogro (na região que se chamaria Jardim América, em homenagem à esposa) e fixou residência na Avenida Paulista. Em sua casa (que daria lugar, na década de 1950, ao Conjunto Nacional), Milliet passou parte de sua infância. Foi o tio Horácio, realça Milliet, quem subvencionou seus estudos na Suíça na juventude: "Sempre recordarei com ternura esse tio Horácio que me deu a oportunidade de estudar na Europa. E outras oportunidades me houvera dado, sem dúvida, se não esbarrasse, no sobrinho, com uma trêfega inquietação e uma rebeldia indomável" (MILLIET, 1962, p. 69).

34 Sobre os demais, Christian Vayas, $M^{\text {me }}$ E. Kiehl, $M^{\text {me }}$ G. P. e Y. B., não se encontrou nenhuma notícia biográfica (no caso dos dois últimos, nomeados por siglas - agraciamento que se assemelha à dedicatória de exemplar, visto que a opção pela preservação do 
algum affair, esquivando-se de fazê-lo, entretanto, com familiares do tronco paterno...

No quadro de epigrafados - na capa, Nietzsche, e à frente de poemas, Mugnier, Samain e Chaves -, inclui-se Émile Verhaeren, cujos versos foram por duas vezes em Par le sentier postos em exergo em início de seção. ${ }^{35}$ Sobre a possível absorção de temas ou poética do escritor belga nessa e nas obras subsequentes de Milliet, ${ }^{36}$ cabe mencionar, mais do que as esporádicas alusões a seu nome no Diário crítico, o já citado artigo de título baudelairiano "Um poeta da vida moderna", de Quatro ensaios. Nesse estudo, Milliet aprecia - sem cair nos julgamentos saintebeuvianos, que execrava - a obra do autor das Campagnes hallucinées à luz de sua biografia. De versos sensuais e de tendência naturalista, nos quais se entreviam traços de Coppée e Baudelaire, Verhaeren teria, como consequência de suas dificuldades financeiras e decepções amorosas, avançado para uma poesia marcada pela dúvida e pela tristeza, expressas, porém, segundo o exuberante temperamento flamengo. Seu "sentimento do mundo", fortalecido pelas leituras de Whitman e Nietzsche, manifestarse-ia, afirma Milliet, em versos que cantavam o heroísmo do proletário tiranizado por ciclópicas cidades e que condenavam o sofrimento do homem. No ensaio de 1966, um dos últimos de sua lavra, Sérgio Milliet retoma, en bouclant la boucle, o verso que citara em seu livro inicial: "La vie est à monter, et non pas à descendre”. Contudo, é por meio de referências a obras como Les heures claires e Les heures du soir que ele torna evidente aqueles que seriam, da vasta produção poética de Verhaeren, os títulos e os temas, de fundo romântico, que o teriam arrebatado na juventude ("Exatamente com dezoitos anos, ainda estudante da Universidade de Genebra, publicava meu primeiro livro de poesias: Par le sentier. Eu era um sofredor, por temperamento e circunstâncias momentâneas, um sofredor apaixonado", confessara Milliet em passagem supratranscrita dos

anonimato do homenageado equivale a um veto de sua identificação pelo leitor -, tampouco a identidade).

35 Em "Le chemin des sens": "Le don du corps, lorsque l'âme est donnée,/ N'est rien que l'aboutissement/ De deux tendresses entraînées/ L'une vers l'autre, éperdument” [O dom do corpo, quando as almas são dadas, / É tão somente o desenlace/ De duas ternuras levadas,/ Ardentemente, face a face] (p. 47), de Les heures claires (1896); em "Vers la Joie": "La vie est à monter, et non pas à descendre" [A vida é pra subir, e não para baixar] (p. 115), de La multiple splendeur (1906).

36 Excetuando-se estudos como os de Lopez (1996) sobre as matrizes de Há uma gota de sangue em cada poema e Pauliceia desvairada, são raros os trabalhos que abordam, ainda que transversalmente, a recepção da obra de Verhaeren no Brasil. 
Ensaios de 1938). Eis, talvez, a razão pela qual tais volumes apareçam na crítica millietiana, ainda na década de 1960, com um relevo que não é facultado às Villes tentaculaires, livro ao qual, em aparente contradição, o título do ensaio indiretamente remete.

De rimas (cruzadas, emparelhadas ou interpoladas, com alternância, segundo tradição da poesia francesa, entre as formas masculina e feminina), estruturas (com preeminência de quartetos e sonetos, estes últimos em formatos diversos) e metros variados (em que predominam, em mais da metade do conjunto, dodecassílabos, a que se sucedem, em número de ocorrências, octo e heptassílabos), Par le sentier é um livro feito sob medida. ${ }^{37}$

Sem medida é, todavia, seu eu lírico. Essa voz, que seguidamente alude ao momento da escrita, expõe, ora à amada, ora aos leitores, o sofrimento decorrente de suas desilusões amorosas; confessa seu desalento, descrença e incapacidade de repelir os sentimentos e sensações que tal mulher lhe desperta, posto serem essas emoções e estímulos a causa de seus tormentos; e flerta com a Morte até encontrar, nos versos finais, o verdadeiro Ideal (a Arte, não o Amor). É à noite, na dura viagem ao redor do quarto, que o poeta amarga a distância da amada e materializa, na e pela literatura, sua dor juvenil:

Fille, je pense à toi ce soir

La nuit est froide et noire; il vente $3^{8}$

*

Et moi, tout seul, je pleure une amante lointaine ${ }^{39}$

En ce moment tout dort et j'entends seulement

Le bruit très sec et doux que fait ma cigarette,

Ou bien sur ce papier le léger grincement

De ma plume amoureuse; et pensif je marrête..$^{\circ}$

37 Dos quarenta e oito poemas que constituem o volume, apenas um - aquele dedicado à mãe - não tem métrica ou estrutura definida (conquanto preserve as rimas).

38 "Moça, em ti penso nesta noite/ A noite é fria e sombria, venta." (p. 59).

39 "E eu, tão sozinho, choro uma amante distante." (p. 88).

40 "Agora tudo dorme e tenho só ouvido/ De meu cigarro o som ameno e crepitante,/ Ou sobre este papel o suave gemido/ De minha ardente pluma; e eu me quedo distante." (p. 57). 
A despeito de uma controversa divisão em ciclos, na qual apenas a última seção, "Rumo à Alegria”, tem um colorido específico (as demais são ilustradas em "meios-tons" indistintos de um bloco a outro), a unidade do conjunto é patente: da primeira parte, "Ideal", ${ }^{41}$ à penúltima, "Lassidões", acompanha-se o calvário do poeta (cuja existência subjetiva, em Par le sentier, impõe-se à realidade objetiva), se não in loco - na medida em que, não fossem a única menção ao maciço montanhoso que cerca uma parte de Genebra $^{42}$ e as quase imateriais alusões ao inverno, à neve ou às folhas que caem no outono, não há indicações precisas do lugar em que se encontra o eu-lírico -, ao menos pari passu. Sob uma convincente roupagem formal, Milliet, à moda de Baudelaire e Verlaine, retoma e elabora - mediante o emprego de recursos caros à poesia simbolista (dentre os quais o apelo à sinestesia, ao sensorial, ao musical, a maiúsculas alegorizantes e a tópicas secularmente consagradas na poesia europeia, como o memento mori e a inacessibilidade da mulher amada, com um retoque de femme fatale da Belle Époque) - temas próprios da modernidade oitocentista: solidão, abandono, desencontros amorosos, tédio e silêncio.

\author{
Au désert des grandes places, \\ Où la foule passe et passe, \\ Mon âme est très seule et lasse. \\ Une larme lente roule... \\ J'ai honte devant la foule \\ De cette larme qui roule. ${ }^{43}$
}

\begin{abstract}
41 Foge ao escopo deste texto investigar o possível vínculo entre o "ideal" evocado nessa obra e os "idealismos" em voga na Europa ao longo da segunda metade do século XIX (mormente a partir do final do decênio de 1880). A crítica, afirma Rapetti (2016), tende a indicar como fontes possíveis do ideal simbolista a filosofia neoplatônica e o romantismo alemão. É plausível supor que o jovem Milliet, estudante de Ciências Econômicas e Sociais, estivesse menos familiarizado com obras filosóficas do que com literárias (em que "ideal", "ideia", "idealismo" e termos congêneres abundavam). O emprego de "Ideal" como título de seção (à semelhança das Flores do mal, que, em sua primeira edição, se dividia em cinco ciclos, sendo o primeiro deles "Spleen et Idéal") minimamente revela um autor que era leitor afeito à poesia fin de siècle.

42 "Le Jura s'évanouit.../ Regarde tomber la nuit." [O Jura desfalece.../ Veja cair a noite.] (p.35), versos em que se notam, além da forçada diérese na última palavra do primeiro verso, a mal arranjada rima \nwi $\backslash$ e \nui \ (imperfeição rara, diga-se de passagem, no volume).

43 "No vazio da grande praça,/ Onde o povo passa e passa,/ Minha alma é tão só e lassa.// E despenca um pranto lento.../ Ante o povo que tormento/ Me inflige este pranto lento." (pp. 101-102).
\end{abstract}


Dans l'air mélancolique

Où pleure une musique

Nostalgique,

[...]

Sur tes cheveux qui tremblent,

Nos deux âmes ensemble

Se ressemblent. ${ }^{44}$

Le silence est angoissant,

Lentement le soir descend. ${ }^{45}$

J'ai le goût de la mort qui m'effleure la bouche, J'appelle le malheur sur tout ce que je touche. ${ }^{46}$

Je suis seul dans ma chambre et ma douleur s'avive...

Et je pleure parfois et je serre les poings. ${ }^{47}$

Os fragmentos supraditos não apenas atestam as por diversas vezes ressaltadas marcas baudelairianas no livro de estreia de Sérgio Milliet, mas, sobretudo, confirmam o quão verlainianos soam muitos desses versos (especialmente os de métrica curta). É igualmente relevante acentuar, antes que se encerre esta breve apresentação de Par le sentier, a presença nessa obra de um dos expoentes da poesia francesa finissecular, Albert Samain, citado por Milliet como epígrafe no soneto que segue:

Il est des soirs d'automne où je te sens très proche,

Où je sens que ta chair a frissonné en moi,

Où dans un air plus tendre et tout empli d'émois

Voltigent doucement de timides reproches.

Ces soirs tout est tranquille et mystique et flottant, Et l'étoile palpite et la lune s'enflamme;

Des senteurs de fleur morte et des parfums de femme,

D'une douceur étrange et lointaine d'antan,

Entrent dans mon alcôve à flots par la fenêtre.

Ces soirs le souvenir de notre grand amour

Vient à moi comme un souffle et caresse mon être;

44 "Na brisa melancólica/ Em que chora uma música/ Tão nostálgica,// [...] // Nos teus cabelos trêmulos/ Juntos, nossos espíritos/ São análogos.” (p. 41).

45 "O silêncio é afligente,/ Lentamente a noite pende." (p. 33).

46 "Sinto o gosto da morte que chega à minha boca,/ Eu atraio a desgraça a tudo que me toca." (p. 68).

47 "Estou só em meu quarto e minha dor se aviva.../ E por vezes pranteio e calado eu engulo." (p. 103). 
Et je ressens sur moi ta bouche aux fins contours,

Et fougueuse et timide et douce tour à tour.

Ces soirs le souvenir de tes lèvres s'approche...

Et je te sais très loin mais je te sens très proche. $4^{8}$

O soneto é a forma de composição mais recorrente em Par le sentier (dezoito poemas, ou seja, mais de um terço do total). À estrutura mais usual (catorze versos distribuídos em dois quartetos e dois tercetos) Milliet acrescenta outras três: no poema inicial, "Dédicace", dispõe os versos em duas estrofes apenas (uma oitava e uma sextilha); em três ocasiões, em cinco estrofes (um dístico e quatro tercetos); e, em quatro, como é o caso do poema supratranscrito, adiciona um décimo-quinto verso, sob a forma de monóstico, no final. Se não o inventor, muito verossimilmente Samain terá sido o poeta que mais compôs sonetos com essa característica: na reedição de 1911 de sua obra mais conhecida, Au jardin de l'infante, há seis sonetos de quinze versos! $49 \mathrm{O}$ fato de não ter, em seu livro inicial, aderido ao verso livre não significa, evidentemente, que Milliet não tenha realizado pesquisas no âmbito da forma, e seus variados tipos de soneto, com soluções rítmicas igualmente diversificadas, são um exemplo desse esforço. De Samain, Milliet teria apreendido não apenas uma nova configuração para uma velha forma, mas, provavelmente, também o uso de alguns mecanismos de repetição, como revela, aliás, o poema do qual provém a epígrafe de "Il est des soirs d'automne", "Il est d'étranges soirs", de que se reproduz os quatro versos iniciais (sendo o primeiro deles o transcrito por Milliet na epígrafe).

\footnotetext{
Il est d'étranges soirs, où les fleurs ont une âme,

Où dans l'air énervé flotte du repentir,

Où sur la vague lente et lourde d'un soupir

Le cœur le plus secret aux lèvres vient mourir. ${ }^{50}$
}

\footnotetext{
48 "Há noites outonais em que perto te sinto,/ Em que sinto fremir na minha pele a tua,/ Em que com emoção em ar brando flutua/ Lenta e timidamente um reparo sucinto.// Nessas noites tudo é místico, calmo e movediço,/ A lua resplandece e brilham as estrelas;/ Perfumes de flor morta e aromas de donzelas, / De singular e doce e remontado viço,// Pela janela adentram, em ondas, na alcova minha./ Às noites, a lembrança de nosso grande amor/ Vem a mim como um sopro e o meu ser acarinha;// E sinto tua boca talhada com primor/ Com contínua doçura, timidez e ardor./ Cresce à noite a lembrança de teu lábio retinto...// Sei-te longe, meu bem, porém perto te sinto." (pp. 53-54).

49 "Automne", "Keepsake", "Galswinte", "La tour", "Fleurs suspectes" e "Midi". Nas obras posteriores, há ao menos outros dez sonetos com a mesma conformação.

50 "Há singulares noites em que as flores têm alma,/ Em que no ar agitado plana o arrependimento,/ Em que na vaga lenta e densa de um lamento/ vem nos lábios morrer o oculto sentimento."
} 
As quatro sextilhas que constituem o poema de Samain têm a mesma estrutura: às locuções iniciais do primeiro verso de cada estrofe ("étranges soirs", "clairs matins", "mornes jours" e "nuits de doute") seguem as características das fases do dia - que, afinal, não representam senão as fases da vida -, introduzidas sempre do mesmo modo (pelo relativo "où" e pelo demonstrativo "ces [soirs / matins / jours / nuits]-là").

Em seu soneto, Milliet muda o tópos (a fuga do tempo cede lugar à lembrança da mulher amada), mas reaproveita o arranjo composicional de Samain ${ }^{11}$ e adiciona às repetições do conectivo "où" e da locução "ces soirs" a retomada do final do primeiro verso no remate do último ("je te sens très proche"), em ritornello. O bom uso de figuras de retórica - como a personificação, a sinestesia e a antítese - põe em evidência a sensibilidade do leitor e o esmero do escritor, e anuncia uma preocupação com o "artefazer", que se tornará marca registrada do futuro crítico de arte.

Treze comentários, editados em apêndice em Le départ sous la pluie (1919), indicam como Par le sentier foi recebido no momento do lançamento e nos meses subsequentes à publicação. Baudouin e Mugnier subscrevem duas notas cada um (a segunda, extraída dos textos de apresentação estampados no livro de estreia), a que se juntam fragmentos impressos em periódicos de Genebra (dentre os quais Le Carmel), da lavra de Charles Reber, Jules Cougnard, Jean Secrétan e Jean Violette, duas notícias anônimas (uma delas veiculada em um jornal parisiense) e excertos de críticas de Rodrigo Otávio Filho, João Ribeiro e Guilherme de Almeida, que vieram a lume em números das revistas Panóplia (SP), Imparcial (RJ) e A Cigarra (SP), nos anos de 1917 a 1919. Em apenas três dos comentários publicados na Europa faz-se alusão à origem estrangeira do autor, sendo dois deles as reedições de passagens dos textos introdutórios de Par le sentier. Às observações de Mugnier e Baudouin, soma-se esta nota, não assinada, reproduzida no parisiense Le Pays: "C'est un tour

\footnotetext{
51 Em tempo: Milliet faz duas breves alusões a Albert Samain em seu Diário crítico. Na primeira (MILLIET, 1981a, p. 8), afirma que o tom elegíaco dos versos de Lume de estrelas, de Alphonsus de Guimarães Filho, recorda a poesia do autor francês; na segunda, ao comentar Tuberculose e literatura, de Túlio Hostílio Montenegro, proclama: "É verdade que Baudelaire, romântico de espírito, é um cultor da forma, um pré-parnasiano. Entretanto, a tuberculose, pulando a escola da impassibilidade, foi tornar-se íntima dos simbolistas. Laforgue e Samain são protótipos do tuberculoso pulmonar" (MILLIET, 1981b, pp. 106107).
} 
de force, dans une langue qui n'est pas la sienne, d'avoir su traduire une sensibilité toute chaude du soleil natal". ${ }^{22}$

Os brasileiros, por sua vez, sublinham a qualidade composicional e a potência lírica dos versos de Milliet, que, aliás, é mais uma vez comparado ao autor das Fêtes galantes: "Um Verlaine filtrado pelos trópicos", ajuíza Guilherme de Almeida. Um Verlaine "aclimatado",53 portanto. Os comentadores genebrinos secundam Mugnier e Baudouin à letra: aqueles, como estes, sinalizam o caráter confessional do livro (que refletiria uma crise já em via de dissolução) e descortinam nos poemas amorosos do principiante um talento promissor. Embora estivesse em um continente assolado pela guerra, Milliet passou ao largo de debates de ordem social e política. Exceto Mugnier (que, como já assinalado, defende o não envolvimento do poeta na contenda europeia), os demais críticos tomam distância da polêmica e não abordam a questão do engajamento. Salvo uma volátil alusão ao calor tropical, tampouco consignam traços na poética de Milliet que possam distingui-la da de seus pares locais. É crível supor, por conseguinte, que tenham examinado Par le sentier com os parâmetros de que igualmente se serviam para apreciar as obras de seus conterrâneos. Se há condescendência no julgamento deles, o motivo decerto não é a nacionalidade do autor estreante, mas o fato - que não se pode desconsiderar - de serem, críticos e criticado, colegas de confraria.

As aspirações dos poetas fin de siècle, que Décaudin (1981, p. 19) precisa como "recusa do mundo positivista, das solicitações políticas e sociais, das realidades materiais, das convenções e das obrigações da vida civilizada", ${ }^{4}$ consubstanciam-se, em larga escala na poesia simbolista, em versos nos quais prevalece o lirismo íntimo. Seguindo os ditames de uma corrente estética, que, em 1917, agonizava, Milliet apresenta como tema de seu primeiro livro a desilusão amorosa, a "volúpia dolorosa”. 55 Quarenta e cinco anos depois, o escritor sentenciará: “[...] aos vinte [anos] a única preocupação é o amor, e [...] nessa idade todo amor é infeliz, porque se dá demais e não se recebe quanto se deseja" (MILLIET, 1962, p. 21).

52 "Traduzir uma sensibilidade aquecida pelo sol natal em uma língua que não é a sua é uma proeza." (MILLIET, 1919, p. 118).

53 V. Amaral (1996), Aclimatando Baudelaire.

54 “[...] refus du monde positiviste, des sollicitations politiques et sociales, des réalités matérielles, des conventions et des contraintes de la vie policée".

55 "Música da Morte", de Cruz e Sousa. 
Seus poemas, que não terão tido por estímulo tão somente o anseio de purgar suas dores, a "cura pela escrita", mas, muito provavelmente, igualmente o propósito de deslumbrar namoradas e cativar amizades, foram, ao fim e ao cabo, um importante instrumento de sociabilidade e facultaram a seu autor a inserção no círculo literário pelo qual trafegaram nomes como Stefan Zweig e Romain Rolland. A escolha do idioma não se nos afigura como vontade consciente de superar os modelos gauleses, de figurar no rol de autores francófonos ou, indireta e sinuosamente, de elevar a literatura brasileira ao patamar das europeias, mas antes como o resultado de uma acomodação ao espaço geográfico e literário em que o aspirante a escritor, que já falava francês ao embarcar para a Europa, ${ }^{56}$ se encontrava, fator a que talvez se tenha aliado o desejo de reatar, por meio da língua francesa, laços com a ascendência materna (e, ao mesmo tempo, repudiar a família paterna, como igualmente atesta a recusa do uso do sobrenome Costa e Silva).

Por fim, vale lembrar que no ano em que Sérgio Milliet lança seus poemas neorromântico-simbolistas, outro estreante, Mário de Andrade, publica Há uma gota de sangue em cada poema. Sob a égide de Verhaeren (que Milliet tanto conhecia), o professor de piano do Conservatório mostra-se, ao menos em seus versos, mais conectado às adversidades do mundo contemporâneo do que o estudante de Ciências Econômicas e Sociais de Genebra. Surpreende pensar que será na provinciana Pauliceia que Milliet, após quase dez anos de temporada europeia, adentrará a literatura do séculoXX - em um processo de reterritorialização que incluirá o retorno ao português como língua de expressão literária - e percorrerá, com os alegres grupos de Klaxon e Terra Roxa, veredas muito distintas daquelas trilhadas no Jura com os amigos do Carmel. Sua obra imatura em língua francesa reflete-se, no entanto, em seus escritos posteriores, do caudaloso Diário crítico a Três conferências e Quatro ensaios, do romance autobiográfico Roberto ao memorialista De ontem, de hoje, de sempre, e revela-se - como este texto espera ter confirmado - de grande interesse para os estudiosos da obra millietiana.

56 Estudar na Europa, como frisa Mindlin (1998) em declaração sobre Rubens Borba de Moraes, era por vezes mais barato do que estudar em São Paulo! Sérgio e Rubens tornamse, aliás, grandes amigos na Suíça. 


\section{SÉRGIO MILLIET'S LITERARY DÉBUT: PAR LE SENTIER}

Abstract: In 1917, in Geneva, Sérgio Milliet published a collection of neoromanticsymbolist poems written "in the manner of" Baudelaire, Verlaine and Samain: Par le sentier. Absent from the catalog of the main libraries of Brazil, the first work of one of the most prominent names of Brazilian literary and art criticism in the 2oth century remains unknown to the public. Thus, the main purpose of the present text is to introduce a few comments about this debut piece and add some biographical notes about Milliet's first visit to Europe and about Carmel, the literary group in charge of the journal in which Milliet published his first poems and of the publishing house that printed Par le sentier. Keywords: Sérgio Milliet; Poetry; Symbolism.

\section{$\overline{\text { REFERÊNCIAS }}$}

ALAMBERT JÚNIOR, Francisco. Um melancólico no auge do modernismo: Sérgio Milliet (uma trajetória no exílio). Dissertação (Mestrado em História) - Faculdade de Filosofia, Letras e Ciências Humanas da Universidade de São Paulo, 1991.

AMARAL, Glória Carneiro do. Aclimatando Baudelaire. São Paulo: Annablume, 1996.

ANDRADE, Mário de. O movimento modernista. In: Aspectos da literatura brasileira. São Paulo: Martins Editora, 1978, pp. 231-255.

BIVAR, Vanessa dos Santos Bodstein. Vivre à St. Paul: os imigrantes franceses na São Paulo oitocentista. Tese Doutorado em História) - Faculdade de Filosofia, Letras e Ciências Humanas da Universidade de São Paulo, 2007.

BLUM, Antoinette. L'Europe vue du Carmel (1916-1918). Equinoxe: Revue des Sciences Humaines, Friburgo, n. 17, 1997, pp. 37-53.

BLUM, Antoinette. Le Carmel, 1916-1918: une revue genevoise d'inspiration européenne. La Revue des Revues, Paris, n. 25, 1998, pp. 67-81.

BOAVENTURA, Maria Eugenia. 22 por 22: A Semana de Arte Moderna vista pelos seus contemporâneos. São Paulo: Edusp, 2010.

BRITO, Mário da Silva. O alegre combate de Klaxon [texto introdutório]. Klaxon - Mensário de Arte Moderna de São Paulo, São Paulo, Martins/SCET, 1972. (edição fac-similada)

CAMPOS, Regina Maria Salgado. Sérgio Milliet e Henri Mugnier, uma amizade duradoura. In: GONÇALVES, Lisbeth Rebollo (org.). Sérgio Milliet: 100 anos - trajetória, crítica de arte a ação cultural. São Paulo: ABCA/Imprensa Oficial, 2005, pp. 127-138.

CAMPOS, Regina Maria Salgado. Ceticismo e responsabilidade: Gide e Montaigne na obra crítica de Sérgio Milliet. São Paulo: Annablume, 1996.

DÉCAUDIN, Michel. La crise des valeurs symbolistes (1895-1914). Genebra/Paris: Slatkine, 1981. 
GONÇALVES, Lisbeth Rebollo. Sérgio Milliet, crítico de arte. São Paulo: Perspectiva/ Edusp, 1992.

GONÇALVES, Lisbeth Rebollo (org.). Sérgio Milliet: 100 anos - trajetória, crítica de arte a ação cultural. São Paulo, ABCA/Imprensa Oficial, 2005.

LARA, Cecília de. Klaxon e Lumière. Caravelle, Toulouse, n. 25, 1975, pp.77-102.

LE CARMEL: Revue Mensuelle de Littérature, de Philosophie et d'Art, Genebra, n. 1-21, 19161918.

LOPEZ, Telê Porto Ancona. Mariodeandradiando. São Paulo: Hucitec, 1996.

MILLIET, Sérgio. Par le sentier. Genebra/Paris: Éditions du Carmel, 1917.

MILLIET, Sérgio. Le départ sous la pluie. São Paulo/Genebra: Édition du Groupe Littéraire Jean Violette, 1919.

MILLIET, Sérgio. Roberto. São Paulo: Niccolini, 1935.

MILLIET, Sérgio. Ensaios. São Paulo: Brusco, 1938.

MILLIET, Sérgio. De ontem, de hoje e de sempre: recordações com devaneios. Vs. 1 e 2. São Paulo: Martins Editora, 1960-1962.

MILLIET, Sérgio. Quatro ensaios. São Paulo: Martins, 1966.MILLIET, Sérgio. Diário crítico (1945). v. III, São Paulo, Martins, 1981a[1945].

MILLIET, Sérgio. Diário crítico (1949-1950). V. VII. São Paulo: Martins, 1981b[1953].

MILLIET, Sérgio. Diário crítico (1951-1953). V. VIII. São Paulo: Martins, 1981c[1953].

MILLIET, Sérgio. Uma semana de arte moderna em São Paulo; A jovem literatura brasileira. Revista do Instituto de Estudos Brasileiros, São Paulo, n. 34, 1994, pp. 199-210.

MILLIET, Sérgio. Poèmes modernistes E autres écrits. Anthologie 1921-1932. Textes originaux français ou traduits du brésilien. Choix, traduction, présentation et notes par Antoine Chareyre. Toulon: La Nerthe, 2010.

MILLIET, Sérgio; REBER, Charles. En singeant...: pastiches littéraires. Genebra: Atar, 1918.

MINDLIN, José. Rubens Borba de Moraes: um intelectual incomum. Revista Brasileira de Estudos Pedagógicos, v. 79, n. 192, Brasília, 1998, pp. 108-111.

NEME, Mário. Plataforma da Nova Geração. Porto Alegre: Globo, 1945.

RAMOS, Péricles Eugênio da Silva. Sérgio Milliet e o Modernismo. Revista do Instituto de Estudos Brasileiros, São Paulo, n. 5, 1968, pp. 47-64. 
Remate de Males, Campinas-SP, v.38, n.2, pp. 990-1017, jul./dez. 2018 - 1017

RAPETTI, Rodolphe. Le symbolisme. Paris: Flammarion, 2016.

SAMAIN, Albert. Euvres poétiques complètes. Édition critique par Christophe Carrère. Paris: Classiques Garnier, 2015.

SERRANO, Pedro Bueno de Melo. A crítica bandeirante (1920-1950). Dissertação (Mestrado em Sociologia) - Faculdade de Filosofia, Letras e Ciências Humanas da Universidade de São Paulo, 2016.

SILVA, Renata Rufino da. O “contra-modernismo”: internacionalismo e mediação cultural de Sérgio Milliet nos anos 1920. In: Anais do XXVIII Simpósio Nacional de História. Florianópolis, 2015, pp. 1-14.

VELloso, Monica Pimenta. Revistas e redes literárias: reflexões sobre a Lumière. Revista Territórios e Fronteiras, Cuiabá, v. 9, n. 2, 2016, pp. 43-63.

VIOLETTE, Jean. Un modeste cénacle littéraire. Tome LV. Genebra : Bulletin de l'Institut National Genevois, 1952. 